\title{
Emergency department use by people with HIV in Ontario: a population-based cohort study
}

\author{
Ryan Ng MSc, Claire E. Kendall MD PhD, Ann N. Burchell PhD, Ahmed M. Bayoumi MD MSc, \\ Mona R. Loutfy MD MPH, Janet Raboud PhD, Richard H. Glazier MD MPH, Sean B. Rourke PhD, \\ Tony Antoniou PhD
}

\section{Abstract}

Background: Emergency department use may reflect poor access to primary care. Our objective was to compare rates and causes of emergency department use between adults living with and without HIV.

Methods: We conducted a population-based study involving Ontario residents living with and without HIV between Apr. 1, 2011, and Mar. 31, 2012. We frequency matched adults with HIV to 4 HIV-negative people by age, sex and census division, and used randomeffects negative binomial regression to compare rates of emergency department use. We classified visits as low urgency or high urgency, and also examined visits for ambulatory care sensitive conditions. Hospital admission following an emergency department visit was a secondary outcome.

Results: We identified 14534 people with HIV and 58136 HIV-negative individuals. Rates of emergency department use were higher among people with HIV (67.3 v. 31.2 visits per 100 person-years; adjusted rate ratio 1.58, 95\% confidence interval [CI] 1.511.65). Similar results were observed for low-urgency visits. With the exception of hypertension, visit rates for ambulatory care sensitive conditions were higher among people with HIV. People with HIV were also more likely than HIV-negative individuals to be admitted to hospital following an emergency department visit (adjusted odds ratio 1.55, 95\% $\mathrm{Cl} 1.43-1.69$ ).

Interpretation: Compared with HIV-negative individuals, people with HIV had high rates of emergency department use, including potentially avoidable visits. These findings strongly support the need for comprehensive care for people with HIV.

$\mathrm{E}$ mergency department use, particularly for nonurgent conditions, is a frequently used indicator of access to primary care. ${ }^{1}$ Understanding patterns of emergency department use is therefore necessary for optimizing resource allocation and identifying possible gaps in outpatient care. Yet, in contrast to studies examining inpatient and outpatient health care use, ${ }^{2-6}$ comparatively few contemporary studies exist examining emergency department use among people with HIV. ${ }^{711}$ Studies conducted in the years preceding the introduction of combination antiretroviral therapy demonstrated that people with HIV had rates of emergency department visits that were three- to fourfold higher than those of the general population. ${ }^{12,13}$ Although subsequent studies found persistently heightened rates of emergency department use following the introduction of combination antiretroviral therapy, inferences were limited by samples that were small and not population-based. ${ }^{7,9,10} \mathrm{~A}$ recent analysis of the US National Hospital Ambulatory Medical Survey demonstrated that rates of emergency department visits among people with HIV continue to exceed those of noninfected people (633 v. 438 visits per 1000 people), although by a smaller magnitude than during the preceding decade. $^{14}$

Analogous population-based studies characterizing emergency department use among people with HIV in a Canadian setting are lacking. These data are important for several reasons. First, findings generated in the United States are of limited generalizability to the Canadian context because Canadians have access to universally insured and publicly financed health care; consequently, emergency department use should not be influenced by health insurance status. In addition, people with HIV are disproportionately disadvantaged by socioeconomic and structural factors that are associated with poor access to primary care. ${ }^{15}$ In this context, high rates of emergency department use

Competing interests: None declared.

This article has been peer reviewed.

Correspondence to: Tony Antoniou, tantoniou@smh.ca

CMAJ Open 2016. DOI:10.9778/cmajo.20150087 
for conditions that could be potentially managed in ambulatory settings could be emblematic of poor access to primary care and highlight gaps in the community-based management of these patients. Accordingly, we compared rates and causes of emergency department use between adults living with and without HIV in Ontario, Canada. We examined the risk of hospital admission following emergency department visits as a secondary outcome. In light of previously published research, we speculated that people with HIV would have higher rates of emergency department use, including potentially avoidable visits, than HIV-negative individuals.

\section{Methods}

\section{Setting}

We conducted a population-based study comparing rates of emergency department visits between adults (age $\geq 18 \mathrm{yr}$ ) living with and without HIV infection in Ontario between Apr. 1, 2011 and Mar. 31, 2012. This study was approved by the Research Ethics Board of Sunnybrook Health Sciences Centre, Toronto.

\section{Data sources}

We used Ontario's administrative health databases, which were held securely in linkable files without any direct personal identifiers and analyzed at the Institute for Clinical Evaluative Sciences. We identified adults living with HIV using the Ontario HIV Database, an administrative data registry of Ontario residents with diagnosed $\mathrm{HIV}$ infection, which was generated using a validated case-finding algorithm. ${ }^{16}$ The definition of 3 physician claims with an International Classification of Diseases, 9th Revision, code for HIV infection $(042,043,044)$ within a 3 -year period has a sensitivity of $96.2 \%$ (95\% confidence intervals [CI $95.2 \%-97.9 \%)$ and a specificity of $99.6 \%$ (95\% CI $99.1 \%-99.8 \%$ ) for identifying people living with HIV. ${ }^{16} \mathrm{We}$ obtained hospital admission and emergency department data from the Canadian Institute for Health Information's Discharge Abstract Database and National Ambulatory Care Reporting System, respectively. The National Ambulatory Care Reporting System contains detailed clinical information regarding all emergency department visits in Ontario. Recorded data elements include patient demographic variables, service dates and up to 10 diagnostic codes (International Statistical Classification of Diseases and Related Health Problems, 10th Revision [ICD-10]), one of which must be designated as the "main problem," or the most clinically significant reason for the patient's visit to the emergency department. We used the Ontario Health Insurance Plan database to identify claims for physician services, and used validated disease registries to define the presence of diabetes, hypertension, chronic obstructive pulmonary disease, congestive heart failure and asthma. ${ }^{17-21} \mathrm{We}$ obtained basic demographic and date-of-death data from the Registered Persons Database, a registry of all Ontario residents eligible for health insurance.

\section{Study population}

We used the Registered Persons Database to identify all adults in Ontario (age $\geq 18 \mathrm{yr}$ ) who were alive and eligible for health
Table 1: Baseline characteristics of people with HIV and a frequency matched sample of HIV-negative people

\begin{tabular}{|c|c|c|c|}
\hline & \multicolumn{2}{|c|}{ No. $(\%)^{\star}$} & \\
\hline Characteristic & $\begin{array}{c}\text { HIV } \\
n=14534\end{array}$ & $\begin{array}{c}\text { Non-HIV } \\
n=58136\end{array}$ & $\begin{array}{l}\text { Standardize } \\
\text { difference }\end{array}$ \\
\hline
\end{tabular}

Age, yr

\begin{tabular}{|lccc|}
\hline Mean \pm SD & $46.4 \pm 11.0$ & $46.4 \pm 11.0$ & 0.00 \\
\hline $18-25$ & $355(2.4)$ & $1427(2.5)$ & \\
\hline $26-35$ & $1927(13.3)$ & $7703(13.2)$ & \\
\hline $36-45$ & $4468(30.7)$ & $17933(30.8)$ & \\
\hline $46-55$ & $5175(35.6)$ & $20609(35.4)$ & \\
\hline$>55$ & $2609(18.0)$ & $10464(18.0)$ & \\
\hline Sex & & & \\
\hline Female & $2858(19.7)$ & $11432(19.7)$ & 0.00 \\
\hline Male & $11676(80.3)$ & $46704(80.3)$ & \\
\hline
\end{tabular}

Neighbourhood income quintile

5 (highest) $2241(15.4) \quad 11065(19.0) \quad 0.20$

$4 \quad 2171(14.9) \quad 10012(17.2)$

$3 \quad 2348(16.2) \quad 10533(18.1)$

$2 \quad 2999(20.6) \quad 12391(21.3)$

1 (lowest) $4555(31.3) \quad 13606(23.4)$

Missing $220(1.5) \quad 529(0.9)$

Rural residence $\quad 628(4.3) \quad 2898(5.0) \quad 0.03$

No. primary care visits in the past year

$\begin{array}{lccc}\text { Mean } \pm \text { SD } & 6.0 \pm 8.9 & 3.3 \pm 5.2 & 0.43 \\ \text { Median (IQR) } & 4(1-7) & 2(0-4) & \end{array}$

Aggregated diagnosis groups

$\begin{array}{lccc}\text { Mean } \pm \text { SD } & 4.3 \pm 3.1 & 2.7 \pm 2.5 & 0.61 \\ \text { Median (IQR) } & 4(2-6) & 2(1-4) & \end{array}$

Resource utilization band

$\begin{array}{llll}\text { Nonusers } & 856(5.9) & 13032(22.4) & 1.12\end{array}$

Healthy users $204(1.4) \quad 4942(8.5)$

Low resource $\quad 566(3.9) \quad 13778(23.7)$

use

Moderate $\quad 8809(60.6) \quad 22868(39.3)$

resource use

High resource $2869(19.7) \quad 2745(4.7)$

use

$\begin{array}{lll}\text { Very high } & 1230(8.5) \quad 771(1.3)\end{array}$

resource use

\begin{tabular}{lccc} 
Diabetes & $1500(10.3)$ & $6206(10.7)$ & 0.01 \\
\hline Hypertension & $2685(18.5)$ & $12863(22.1)$ & 0.09 \\
\hline COPD & $1469(10.1)$ & $3624(6.2)$ & 0.15 \\
\hline Asthma & $1945(13.4)$ & $5906(10.2)$ & 0.10 \\
$\begin{array}{l}\text { Congestive heart } \\
\text { failure }\end{array}$ & $327(2.2)$ & $677(1.2)$ & 0.09
\end{tabular}

Note: $C O P D=$ chronic obstructive pulmonary disease, $I Q R$ = interquartile range. *Unless stated otherwise. 
insurance as of the index date of the study, Apr. 1, 2011. From within this cohort, we identified people who had been diagnosed with HIV using the Ontario HIV Database. To create a control group that was similar with respect to characteristics that might influence emergency department use, we frequency matched a random sample of HIV-negative residents by age, sex and census division in Ontario to people with HIV in a ratio of 4:1.

\section{Outcomes}

The number of emergency department visits, person-time at risk and rates of overall emergency department use were determined for people living with and without HIV for the study period. We computed rates of emergency department use as the total number of visits occurring during the study period divided by the total person-years of follow-up in the period. For people who died or moved away from Ontario during follow-up, we used an offset to censor their observation at the date of death or migration, such that these individuals only contributed a fraction of a person-year to the rate calculation. We used the "main problem" field in each record to determine the diagnosis most responsible for the visit, and aggregated similar diagnoses into organ- or disease-based categories according to ICD-10 codes.

We defined potentially avoidable visits in 2 ways. First, we used the Canadian Triage and Acuity Scale (CTAS), a standardized measure of the immediacy with which a patient presenting to an emergency department requires care, to categorize emergency department visits as "low urgency" or "high urgency," as has been done in previous studies. ${ }^{22,23}$ Specifically, we considered visits that were triaged as CTAS 4 (less urgent) or 5 (nonurgent) as "low urgency," or representing visits for conditions that could have been potentially managed in ambulatory settings. In contrast, we classified visits triaged as CTAS 1 (resuscitation required), 2 (emergent care required) or 3 (urgent care required) as "high urgency" and likely not preventable. Second, we calculated rates of emergency department visits for ambulatory care sensitive conditions, defined as those conditions for which emergency department use could be potentially avoided with timely and regular access to outpatient care. ${ }^{24}$ We classified conditions as being ambulatory care sensitive using definitions from the literature and the Canadian Institute for Health Information. ${ }^{24-29}$

Table 2: Rates of emergency department visits and regression results for predictors of emergency department visits

\begin{tabular}{|c|c|c|c|c|c|}
\hline \multicolumn{6}{|l|}{ HIV status } \\
\hline Non-HIV & 17967 & 57672.8 & $31.2(29.9-32.5)$ & 1.00 & 1.00 \\
\hline HIV & 9670 & 14370.0 & $67.3(63.6-71.2)$ & $2.19(2.10-2.30)$ & $1.58(1.51-1.65)$ \\
\hline \multicolumn{6}{|c|}{ Neighbourhood income quintile } \\
\hline 4 & 3933 & 12101.2 & $32.5(30.7-34.4)$ & $1.05(0.98-1.13)$ & $1.06(0.99-1.13)$ \\
\hline 3 & 4978 & 12798.6 & $38.9(36.3-41.7)$ & $1.27(1.19-1.36)$ & $1.21(1.14-1.29)$ \\
\hline 2 & 5977 & 15274.5 & $39.1(36.9-41.5)$ & $1.30(1.21-1.38)$ & $1.23(1.16-1.31)$ \\
\hline 1 (lowest) & 8484 & 18015.8 & $47.1(43.5-50.9)$ & $1.55(1.45-1.65)$ & $1.35(1.27-1.43)$ \\
\hline \multicolumn{6}{|c|}{ No. primary care visits in the past year } \\
\hline 0 & 4309 & 18544.3 & $23.2(21.6-25)$ & 1.00 & 1.00 \\
\hline $1-2$ & 5762 & 19538.4 & $29.5(27.7-31.4)$ & $1.27(1.20-1.35)$ & $1.27(1.20-1.34)$ \\
\hline$\geq 3$ & 17566 & 33960.1 & $51.7(49.4-54.1)$ & $2.30(2.19-2.42)$ & $1.47(1.40-1.55)$ \\
\hline \multicolumn{6}{|c|}{$\begin{array}{l}\text { Aggregated diagnosis groups } \\
\text { (prior year) }\end{array}$} \\
\hline $0-5$ & 16263 & 60123.7 & $27.0(26.0-28.2)$ & 1.00 & 1.00 \\
\hline $6-9$ & 7416 & 9979.9 & $74.3(69.9-79.0)$ & $2.79(2.66-7.49)$ & $2.29(2.17-2.41)$ \\
\hline
\end{tabular}


In a separate analysis, we compared the risk of hospital admission following an emergency department visit between people with and without HIV. To ensure comparability in the distribution of factors that may predispose to hospital admission following an emergency department visit, we frequency matched each visit resulting in hospital admission among people with HIV to 4 such visits among non-HIV-infected individuals by patient age, sex and census division within Ontario.

\section{Statistical analysis}

We computed standardized differences to examine intergroup balance in the distribution of baseline variables. Standardized differences of less than 0.1 indicate good balance between groups for a given covariate. ${ }^{30}$

For the primary analysis, we compared rates of emergency department use between people with and without HIV using random-effects negative binomial regression models to account for the correlation among matched groups. To examine the association between HIV infection and hospital admission following an emergency department visit, we used generalized estimating equations with a logit link function and exchangeable correlation structure. We adjusted models for variables that could influence emergency department use and risk of subsequent hospital admission, including the number of visits to a primary care physician in the previous year, urban versus rural residence, socioeconomic status and patient comorbidity in the year preceding the index date. We determined patient socioeconomic status at the neighbourhood level using postal code information and Statistics Canada census data. We used the Johns Hopkins Adjusted Clinical Groups Case-Mix System to adjust for differences in comorbidity burden in the year preceding the index date. ${ }^{31}$ This system uses diagnostic information from administrative databases to describe and predict use of health care resources. In this study, we used aggregated diagnosis groups, which are clusters of diagnostic codes that are similar in terms of severity and expected persistence. The number of aggregated diagnosis groups ranges from 0 to a maximum of 32 , with a higher number reflecting a higher level of comorbidity. We also generated resource utilization bands, which are aggregations of age-sex diagnostic groups associated with different levels of expected resource use, ranging from 0 (lowest expected health care use) to 5 (highest expected health care use), to compare patients based on their expected use of health care resources. Because of collinearity between aggregated diagnosis groups and resource utilization bands, we adjusted models only for the former. For the hospital admission models, we also adjusted for severity of presenting symptoms according to CTAS score; whether the emergency department was located within an academic teaching hospital; and emergency department volume, classified into tertiles as low, medium or high. Because we speculated a priori that patients with HIV would be at heightened risk of admission regardless of visit severity, we examined the interaction between HIV status and CTAS score in a separate model. All analyses were conducted using SAS version 9.3.

\section{Results}

We identified 14534 people with HIV and 58136 matched $\mathrm{HIV}$-negative individuals. The mean age was 46.4 (SD 11.0) years, and about $20 \%$ were women (Table 1). Collectively, these individuals contributed 72043 person-years of follow-up and made 27637 visits to the emergency department between Apr. 1, 2011, and Mar. 31, 2012, of which 9670 (35.0\%) were attributable to people with HIV. Compared with HIV-negative individuals, people with HIV had a greater comorbidity burden as reflected by the number of aggregated diagnosis groups, had more physician visits in the year preceding the index date, had a higher prevalence of chronic obstructive pulmonary disease and were disproportionately represented in the

Table 3: Visits for ambulatory care sensitive conditions among people with and without HIV (per 1000 person-years)

\begin{tabular}{|lccc} 
& \multicolumn{2}{c}{ Rate of visits $(95 \% \mathrm{Cl})$} & \multirow{2}{*}{ Rate ratio (95\% Cl) } \\
\cline { 2 - 3 } Condition & HIV & Non-HIV & $3.30(2.28-4.00)$ \\
\hline Epilepsy & $3.55(2.64-4.67)$ & $1.08(0.82-1.38)$ & $3.26(2.46-4.33)$ \\
\hline Chronic obstructive pulmonary disease & $6.05(4.85-7.47)$ & $1.86(1.52-2.24)$ & $2.24(1.57-3.17)$ \\
\hline Asthma & $3.41(2.52-4.51)$ & $1.53(1.22-1.88)$ & $1.96(1.33-2.88)$ \\
\hline Heart failure & $2.64(1.87-3.63)$ & $1.35(1.07-1.69)$ & $1.73(1.25-2.39)$ \\
\hline Diabetes & $3.62(2.70-4.75)$ & $2.10(1.74-2.51)$ & $1.60(1.23-2.09)$ \\
\hline Dental & $5.36(4.23-6.70)$ & $3.35(2.89-3.85)$ & $1.22(0.82-1.82)$ \\
\hline Angina & $2.23(1.52-3.14)$ & $1.82(1.49-2.20)$ & $5.35(2.74-10.45)$ \\
\hline Gastroenteritis & $1.39(0.85-2.15)$ & $0.26(0.15-0.43)$ & $0.81(0.50-1.31)$ \\
\hline Hypertension & $1.39(0.85-2.15)$ & $1.72(1.40-2.09)$ & $3.90(3.39-4.49)$ \\
\hline Cellulitis & $27.00(24.38-29.83)$ & $6.92(6.26-7.63)$ & $2.07(1.75-2.45)$ \\
\hline $\begin{array}{l}\text { Ears, nose and throat (including upper } \\
\text { respiratory infection) }\end{array}$ & $14.41(12.51-16.51)$ & $6.95(6.29-7.67)$ & \\
\hline Note: Cl = confidence interval. & & & \\
\hline
\end{tabular}




\section{OPEN}

\section{Research}

lowest neighbourhood income quintile (Table 1). Overall, $4065(28.0 \%)$ people with HIV made at least 1 visit to an emergency department during the study period, compared with 10252 (17.6\%) HIV-negative individuals.

After multivariable adjustment, the rate of emergency department visits was higher among people with HIV than among HIV-negative individuals [67.3 v. 31.2 visits per 100 person-years; adjusted rate ratio $1.58,95 \%$ CI $1.51-1.65]$ (Table 2). The unadjusted rates of the most common causes of emergency department visits are shown in Appendix 1, available at www.cmajopen.ca/content/4/2/E240/suppl/DC1. Compared with HIV-negative individuals, people with HIV

\begin{tabular}{|c|c|c|c|}
\hline \multirow[b]{2}{*}{ Characteristic } & \multicolumn{2}{|c|}{ No. $(\%)^{*}$} & \multirow[b]{2}{*}{$\begin{array}{l}\text { Standardized } \\
\text { difference }\end{array}$} \\
\hline & $\begin{array}{c}\text { HIV } \\
n=9670\end{array}$ & $\begin{array}{c}\text { Non-HIV } \\
n=38670\end{array}$ & \\
\hline \multicolumn{4}{|l|}{ Age, yr } \\
\hline Mean \pm SD & $45.62 \pm 12.04$ & $45.62 \pm 12.03$ & 0.01 \\
\hline $18-25$ & $279(2.9)$ & 1122 (2.9) & \\
\hline $26-35$ & 1656 (17.1) & $6762(17.5)$ & \\
\hline $36-45$ & 3034 (31.4) & 12030 (31.1) & \\
\hline $46-55$ & 2921 (30.2) & $11758(30.4)$ & \\
\hline$>55$ & $1780(18.4)$ & $6998(18.1)$ & \\
\hline \multicolumn{4}{|l|}{ Sex, \% } \\
\hline Female & 2260 (23.4) & $9040(23.4)$ & 0.00 \\
\hline Male & 7410 (76.6) & $29630(76.6)$ & \\
\hline \multicolumn{4}{|l|}{ Income quintile } \\
\hline 5 (highest) & $1222(12.6)$ & $5833(15.1)$ & 0.28 \\
\hline 4 & 1126 (11.6) & $6184(16.0)$ & \\
\hline 3 & $1623(16.8)$ & $6832(17.7)$ & \\
\hline 2 & $1918(19.8)$ & 8612 (22.3) & \\
\hline 1 (lowest) & 3646 (37.7) & $10860(28.1)$ & \\
\hline Missing & 135 (1.4) & $349(0.9)$ & \\
\hline Rural residence & $657(6.8)$ & 3269 (8.5) & 0.08 \\
\hline \multicolumn{4}{|c|}{ No. primary care visits in the past year } \\
\hline Mean \pm SD & $10.2 \pm 13.7$ & $6.3 \pm 10.0$ & 0.37 \\
\hline \multicolumn{4}{|l|}{ CTAS score } \\
\hline Nonurgent & $475(4.9)$ & $1851(4.8)$ & 0.09 \\
\hline Less urgent & $2723(28.2)$ & $12430(32.1)$ & \\
\hline Urgent & $4406(45.6)$ & $16816(43.5)$ & \\
\hline Emergent & $1960(20.3)$ & $7235(18.7)$ & \\
\hline Resuscitation & $78(0.8)$ & $250(0.6)$ & \\
\hline \multicolumn{4}{|c|}{ Emergency department volume } \\
\hline High & $7418(76.7)$ & $29950(77.5)$ & 0.02 \\
\hline Low & $479(5.0)$ & $1837(4.8)$ & \\
\hline Medium & $1773(18.3)$ & $6883(17.8)$ & \\
\hline Teaching hospital & $5206(53.8)$ & $11220(29.0)$ & 0.54 \\
\hline \multicolumn{4}{|c|}{ Time in the emergency department, min } \\
\hline Mean \pm SD & $367.0 \pm 498.7$ & $271.0 \pm 361.7$ & 0.24 \\
\hline \multicolumn{4}{|c|}{ Time of arrival in the emergency department } \\
\hline Mean \pm SD & $13: 05 \pm 5.89$ & $13: 14 \pm 5.86$ & 0.01 \\
\hline
\end{tabular}


had high rates of emergency department visits related to infectious diseases (87.27 v. 21.55 visits per 1000 personyears; rate ratio $4.05,95 \%$ CI 3.74-4.38) and mental health illness (62.21 v. 19.73 visits per 1000 person-years; rate ratio $3.15,95 \%$ CI $2.89-3.44)$. The most frequent ( $n=1069$; $42.8 \%$ ) infectious causes of emergency department use were skin and soft-tissue infections, with rates of 36.67 and 9.40 visits per 1000 person-years among people with and without HIV, respectively (rate ratio 3.90, 95\% CI 3.46-4.40). Visits for which HIV was designated as the main problem accounted for $14.9 \%(n=187)$ of infectious diseases-related visits among people with HIV. The most common mental health diagnoses for people with HIV were related to alcohol and substance use, with rates of 34.86 visits per 1000 person-years, compared with 7.73 visits per 1000 person-years among HIVnegative individuals (rate ratio 4.51, 95\% CI 3.97-5.12).

We observed similar results when stratifying according to visit acuity. Specifically, people with HIV had higher rates of visits that were categorized as low urgency $(22.3 \mathrm{v} .11 .2$ visits per 100 person-years; adjusted rate ratio 1.55 , 95\% CI $1.45-1.65$ ) and high urgency (44.9 v. 19.9 visits per 100 person-years; adjusted rate ratio 1.61, 95\% CI 1.53-1.69) (Appendix 2, available at www.cmajopen.ca/content/4/2/E240/suppl/DC1). In addition, people with HIV had higher rates of visits for ambula-

\begin{tabular}{|c|c|c|c|c|}
\hline Variable & $\begin{array}{l}\text { No. hospital } \\
\text { admissions }\end{array}$ & No. visits & $\%(95 \% \mathrm{Cl})$ & Adjusted* OR $(95 \% \mathrm{Cl})$ \\
\hline \multicolumn{5}{|l|}{ HIV status } \\
\hline Non-HIV & 3703 & 38670 & $9.6(9.3-9.9)$ & 1.00 \\
\hline HIV & 1513 & 9670 & $15.6(14.9-16.4)$ & $1.55(1.43-1.69)$ \\
\hline \multicolumn{5}{|l|}{ Income quintile } \\
\hline 5 (highest) & 746 & 7055 & $10.6(9.9-11.3)$ & 1.00 \\
\hline 4 & 728 & 7310 & $10.0(9.3-10.6)$ & $0.96(0.85-1.08)$ \\
\hline 3 & 891 & 8455 & $10.5(9.9-11.2)$ & $0.98(0.87-1.10)$ \\
\hline 2 & 1115 & 10530 & $10.6(10.0-11.2)$ & $0.98(0.88-1.09)$ \\
\hline 1 (lowest) & 1681 & 14506 & $11.6(11.1-12.1)$ & $1.00(0.90-1.11)$ \\
\hline \multicolumn{5}{|l|}{ Residence } \\
\hline Urban & 4906 & 44352 & $11.1(10.8-11.4)$ & 1.00 \\
\hline Rural & 306 & 3926 & $7.8(7.0-8.6)$ & $1.13(0.97-1.32)$ \\
\hline \multicolumn{5}{|c|}{ Aggregated diagnosis groups } \\
\hline $0-5$ & 2717 & 30728 & $8.8(8.5-9.2)$ & 1.00 \\
\hline $6-9$ & 1523 & 11901 & $12.8(12.2-13.4)$ & $1.31(1.22-1.41)$ \\
\hline$\geq 10$ & 976 & 5711 & $17.1(16.1-18.1)$ & $1.69(1.53-1.87)$ \\
\hline \multicolumn{5}{|l|}{ CTAS score } \\
\hline Nonurgent & 23 & 2326 & $1.0(0.6-1.4)$ & 1.00 \\
\hline Less urgent & 260 & 15153 & $1.7(1.5-1.9)$ & $1.84(1.25-2.70)$ \\
\hline Urgent & 2329 & 21222 & $11.0(10.6-11.4)$ & $12.08(8.31-17.57)$ \\
\hline Emergent & 2396 & 9195 & $26.1(25.2-27.0)$ & $34.38(23.60-50.09)$ \\
\hline Resuscitation & 199 & 328 & $60.7(55.4-66.0)$ & $156.73(101.34-236.9)$ \\
\hline \multicolumn{5}{|c|}{ Emergency department volume } \\
\hline Low & 175 & 2316 & $7.6(6.5-8.6)$ & 1.00 \\
\hline Medium & 753 & 8656 & $8.7(8.1-9.3)$ & $0.63(0.52-0.77)$ \\
\hline High & 4288 & 37368 & $11.5(11.2-11.8)$ & $0.61(0.50-0.74)$ \\
\hline \multicolumn{5}{|c|}{ Teaching hospital } \\
\hline No & 3112 & 31914 & $9.8(9.4-10.1)$ & 1.00 \\
\hline Yes & 2104 & 16426 & $12.8(12.3-13.3)$ & $1.12(1.04-1.20)$ \\
\hline
\end{tabular}


tory care sensitive conditions ( 7.9 v. 3.3. per 100 person-years; adjusted rate ratio $1.77,95 \%$ CI $1.60-1.96)$. With the exception of hypertension, rates of emergency department use for individual ambulatory care sensitive conditions were higher among people with HIV (Table 3).

To compare the risk of hospital admission following an emergency department visit, we frequency matched 9670 emergency department visits made by people with HIV to 38670 visits made by HIV-negative individuals by age, sex and geographic residence within the province. Although the distribution of visits by CTAS score was similar between the 2 groups (Table 4), the proportion of visits resulting in hospital admission was higher among people with HIV (15.6\%, 95\% CI 14.9\%-16.4\%) than among HIV-negative individuals (9.6\%, 95\% CI 9.3\%-9.9\%). After multivariable regression, people with HIV were at greater risk of being admitted to hospital than HIV-negative individuals (adjusted odds ratio [OR] 1.55, 95\% CI 1.43-1.69] (Table 5). In an analysis stratified by CTAS score, people with HIV were more likely to be admitted to hospital at all levels of visit severity, with the exception of CTAS 1 (resuscitation required) (Figure 1).

\section{Interpretation}

In our population-based study, we observed higher rates of emergency department use among people with HIV relative to a matched sample of HIV-negative individuals. We found consistent results when considering emergency department use for less urgent visits. We also found higher odds of hospital admis- sion among people with HIV, including for visits triaged as less urgent. Further research is warranted to examine whether community-based interventions that promote access to outpatientbased mental health care, substance use treatment, oral health care and timely primary care could reduce potentially preventable emergency department visits among people with HIV.

Our findings build upon those of other recently published studies. Specifically, rates of emergency department use in our study are similar to those of a US study comparing emergency department use among a nationally representative sample of people with and without HIV. ${ }^{14}$ However, people with HIV in that study were less likely to have private insurance than HIV-negative individuals, whereas our findings, arising from a publicly funded health care system, should not be influenced by such disparities. Our results are also similar to those of a Canadian study involving $438 \mathrm{HIV}$-infected injection drug users, in that the cumulative incidence of emergency department use during the 1-year study period was $63.7 \%$, with skin and soft-tissue infections accounting for $17.6 \%$ of visits. ${ }^{11}$ However, our study was population-based in nature, and therefore included all individuals with HIV who entered care, including those who never injected drugs.

Several intersecting mechanisms may explain our findings. First, previous research has shown that low socioeconomic status is associated with greater use of emergency departments for conditions amenable to outpatient management. ${ }^{23}$ Although matching on geographic residence mitigated between-group differences in socioeconomic status, our previous work has demonstrated that people with HIV are disproportionately

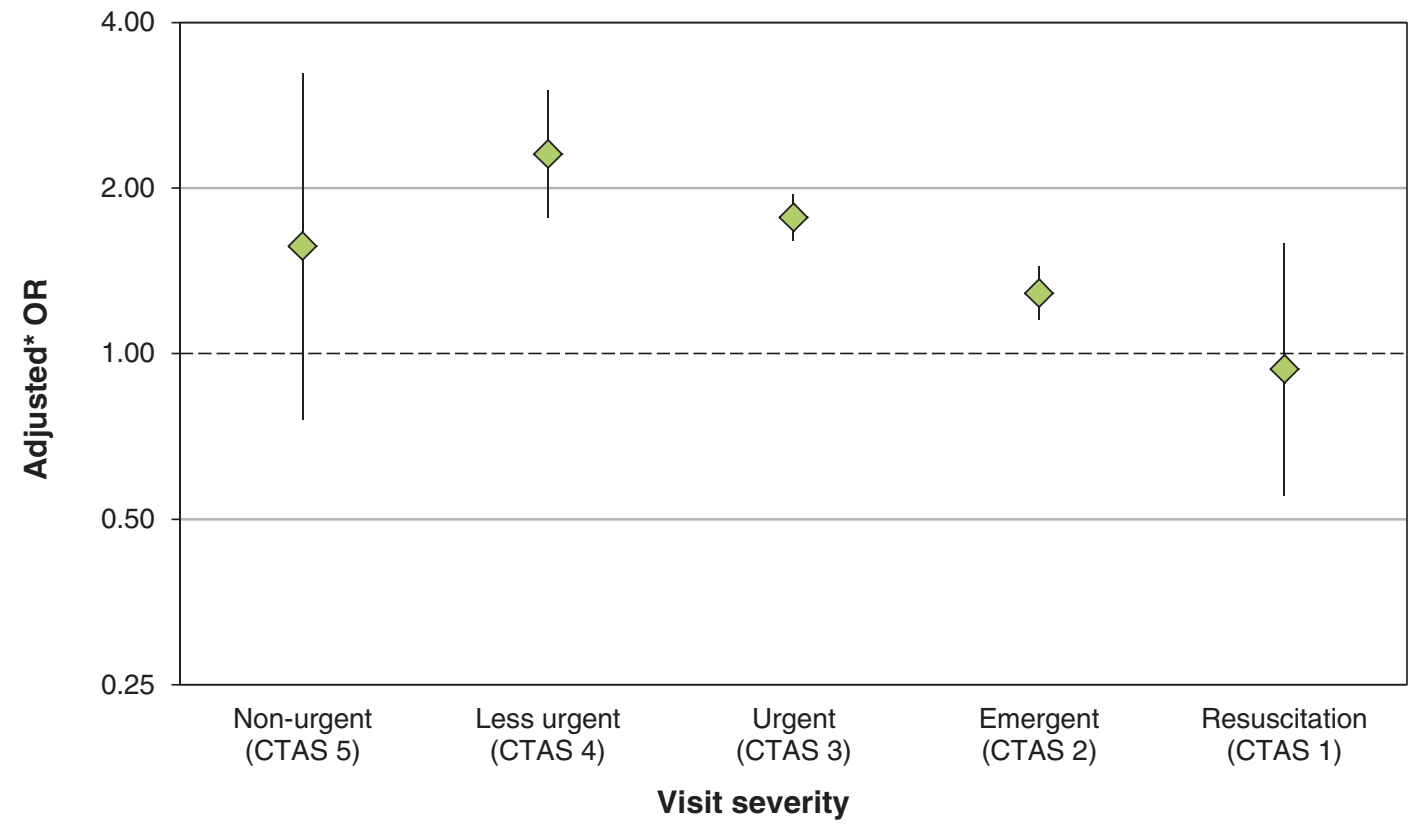

Figure 1: Hospital admission following an emergency department visit among people with HIV compared with HIV-negative individuals, stratified by visit acuity. ${ }^{*}$ Adjusted for socioeconomic status, urban versus rural residence, patient comorbidity, emergency department volume and whether the emergency department was located within an academic teaching hospital. CTAS = Canadian Triage and Acuity Scale, OR = odds ratio. 
represented in low-income neighbourhoods and are more socially and economically marginalized when measures of neighbourhood instability and material deprivation are examined. ${ }^{32,33}$ In addition, ecologic measures of socioeconomic status may not wholly capture the detrimental impact of social determinants such as food and housing insecurity, stigma and unemployment on health outcomes and health services use. These challenges are faced by up to $50 \%$ of Ontario residents with HIV and have been associated with poor health outcomes and heightened rates of emergency department use in several studies. ${ }^{3-38}$ Second, our finding of high rates of emergency department visits related to mental health and substance use could be explained by earlier work highlighting a greater relative burden of mental health-related morbidity among Ontario residents with HIV and less engagement in continuous HIV outpatient care among individuals with a history of injection drug use. ${ }^{39,40}$ Although higher rates of infectious diseases-related visits among people with HIV are not unexpected, only a minority of visits were related to underlying HIV infection. In contrast, skin and soft-tissue infections accounted for most of these episodes in people with HIV, possibly reflecting complications of injection drug use among susceptible individuals. ${ }^{11}$ As of 2011, injection drug use was the mode of acquisition for about $10 \%$ of people living with HIV in Ontario. ${ }^{41}$ Finally, people with HIV had a greater burden of comorbid illness relative to the control population. In addition, some conditions may be more severe among people with HIV. For example, there is evidence that acute exacerbations of chronic obstructive pulmonary disease are almost 3 times more likely to occur among people with HIV than HIV-negative individuals. ${ }^{42}$ Higher rates of emergency department use among people with HIV may therefore reflect appropriate referral by primary care physicians of medically complex individuals to the emergency department. Similarly, clinicians may exercise greater caution in their treatment of individuals with HIV and multiple comorbid conditions, which could account for the higher odds of hospital admission following an emergency department visit among these patients, particularly for conditions triaged as less urgent and nonurgent.

\section{Limitations}

Our findings are strengthened by the population-based nature of our data, which allowed us to examine all Ontario residents with HIV who have entered care. However, our study has some limitations. We used administrative databases and did not have access to laboratory data, including viral load and CD4 cell count, and mode of HIV acquisition. Similarly, we did not have reliable data on antiretroviral use. However, as noted earlier, there were few visits attributable to underlying HIV infection, and an earlier study did not find an association between these indices and emergency department use in people with HIV. ${ }^{11}$ Although we adjusted for comorbidity burden and neighbourhood income quintile, residual confounding related to severity of underlying illness and socioeconomic status is possible. Misclassification or ascertainment bias is possible if a tendency exists to overcall certain diagnoses (e.g., cellulitis, pneumonia) or upgrade the CTAS category in the context of HIV. However, the distribution of CTAS score was similar between people with and without HIV, suggesting that the latter phenomenon is unlikely to have occurred. Although triage level and ambulatory care sensitive conditions are routinely used as indicators of potentially preventable emergency department visits, these definitions have not been validated and do not consider additional patient factors such as degree of comorbidity and social determinants of health. Consequently these visits may not always avoidable, even with timely access to primary care. Finally, we could not identify individuals with undiagnosed HIV and/or people with HIV who have not linked to care; we hypothesize that rates of emergency department visits would be higher in that population.

\section{Conclusion}

We found higher rates of emergency department use among people with HIV relative to the general Ontario population, including for conditions that could be potentially managed in outpatient settings. These findings have important implications for future research and the management of people with HIV. Most notably, they strongly support the focus on comprehensive care for people with HIV set out in Ontario's new provincial strategy (Jean Bacon, Director of Health Policy and Knowledge Translation and Exchange, The Ontario HIV Treatment Network, Toronto: personal communication, 2016). The strategy advocates for early treatment for HIV, clinical guidelines for HIV care that include monitoring for early signs of comorbid conditions that can be managed within primary care settings, timely access to mental health and addiction services, and community-based support programs that address the social and economic determinants of health. In addition, integration of wound care management into existing harm-reduction services may reduce visits for skin and soft-tissue infections associated with injection drug use. Because emergency department use for less urgent conditions is associated with an inability to access timely primary care, we recommend further research to understand impediments to procuring such care among people with HIV. Overall, these efforts will contribute to a more complete understanding of the reasons underlying the observed disparities in emergency department use and ultimately inform programming that optimizes engagement with primary care and management of chronic disease for people with HIV.

\section{References}

1. McCusker J, Roberge D, Lévesque JF, et al. Emergency department visits and primary care among adults with chronic conditions. Med Care 2010;48: 972-80.

2. Bachhuber MA, Southern WN. Hospitalization rates of people living with HIV in the United States, 2009. Public Health Rep 2014;129:178-86.

3. Antoniou T, Zagorski B, Loutfy MR, et al. Socio-economic- and sex-related disparities in rates of hospital admission among patients with HIV infection in Ontario: a population-based study. Open Med 2012;6:e146-54.

4. Yehia BR, Fleishman JA, Hicks PL, et al. Inpatient health services utilization among HIV-infected adult patients in care 2002-2007. 7 Acquir Immune Defic Syndr 2010;53:397-404.

5. Kendall CE, Wong J, Taljaard M, et al. A cross-sectional, population-based study of HIV physicians and outpatient health care use by people with HIV in Ontario. BMC Health Serv Res 2015;15:63.

6. Fleishman JA, Moore RD, Conviser R, et al. Associations between outpatient and inpatient service use among persons with HIV infection: A positive or negative relationship? Health Serv Res 2008;43:76-95. 
7. Kerr J, Duffus WA, Stephens T. Relationship of HIV care engagement to emergency department utilization. AIDS Care 2014;26:547-53.

8. Shih TY, Chen KF, Rothman RE, et al. US national estimation of emergency department utilization by patients given 'HIV/AIDS-related illness' as their primary diagnosis. HIV Med 2011;12:343-51.

9. Josephs JS, Fleishman JA, Korthuis PT, et al.; HIV Research Network. Emergency department utilization among HIV-infected patients in a multisite multistate study. HIV Med 2010;11:74-84.

10. Venkat A, Shippert B, Hanneman D, et al. Emergency department utilization by HIV-positive adults in the HAART era. Int 7 Emerg Med 2008;1:287-96.

11. Fairbairn N, Milloy MJ, Zhang R, et al. Emergency department utilization among a cohort of HIV-positive injecting drug users in a Canadian setting. 7 Emerg Med 2012;43:236-43.

12. Bozzette SA, Berry S, Duan N, et al. The care of HIV-infected adults in the United States. HIV Cost and Services Utilization Study Consortium. $N$ Engl 7 Med 1998;339:1897-904.

13. McCaig LF, Stussman B. National Hospital Ambulatory Medical Care Survey: 1996 emergency department summary. Adv Data 1997;293:1-20.

14. Mohareb AM, Rothman RE, Hsieh YH. Emergency department (ED) utilization by HIV-infected ED patients in the United States in 2009 and $2010-$ a national estimation. HIV Med 2013;14:605-13.

15. Higa DH, Marks G, Crepaz N, et al. Interventions to improve retention in HIV primary care: a systematic review of US studies. Curr HIVIAIDS Rep 2012; 9:313-25.

16. Antoniou T, Zagorski B, Loutfy MR, et al. Validation of case-finding algorithms derived from administrative data for identifying adults living with human immunodeficiency virus infection. PLoS One 2011;6:e21748.

17. Hux JE, Ivis F, Flintoft V, et al. Diabetes in Ontario: determination of prevalence and incidence using a validated administrative data algorithm. Diabetes Care 2002;25:512-6.

18. Tu K, Campbell NR, Chen ZL, et al. Accuracy of administrative databases in identifying patients with hypertension. Open Med 2007;1:e18-26.

19. Gershon AS, Wang C, Guan J, et al. Identifying patients with physiciandiagnosed asthma in health administrative databases. Can Respir 7 2009; 16:183-8.

20. Gershon AS, Wang C, Guan J, et al. Identifying individuals with physiciandiagnosed COPD in health administrative databases. COPD 2009;6:388-94.

21. Schultz SE, Rothwell DM, Chen Z, et al. Identifying cases of congestive heart failure from administrative data: a validation study using primary care patient records. Chronic Dis Inj Can 2013;33:160-6.

22. Murray M, Bullard M, Grafstein E. Revisions to the Canadian Emergency Department Triage And Acuity Scale implementation guidelines. CFEM 2004;6:421-7.

23. Khan Y, Glazier RH, Moineddin R, et al. A population-based study of the association between socioeconomic status and emergency department utilization in Ontario, Canada. Acad Emerg Med 2011;18:836-43.

24. Billings J, Zeitel L, Lukomnik J, et al. Impact of socioeconomic status on hospital use in New York City. Health Aff (Millwood) 1993;12:162-173.

25. Health indicators 2013: definitions, data sources and rationale. Ottawa: Canadian Institute for Health Information; 2013.

26. Roos LL, Walld R, Uhanova J, et al. Physician visits, hospitalizations, and socioeconomic status: ambulatory care sensitive conditions in a Canadian setting. Health Serv Res 2005;40:1167-85.

27. Brown $\mathrm{AD}$, Goldacre MJ, Hicks $\mathrm{N}$, et al. Hospitalization for ambulatory care-sensitive conditions: a method for comparative access and quality studies using routinely collected statistics. Can 7 Public Health 2001;92:155-9.

28. Johnson PJ, Ghildayal N, Ward AC, et al. Disparities in potentially avoidable emergency department (ED) care: ED visits for ambulatory care sensitive conditions. Med Care 2012;50:1020-8

29. Falik M, Needleman J, Wells BL, et al. Ambulatory care sensitive hospitalizations and emergency visits: experiences of Medicaid patients using federally qualified health centers. Med Care 2001;39:551-61.

30. Austin PC, Grootendorst P, Anderson GM. A comparison of the ability of different propensity score models to balance measured variables between treated and untreated subjects: a Monte Carlo study. Stat Med 2007;26: 734-53.

31. The Johns Hopkins ACG System [home page]. Baltimore: Johns Hopkins University. Available: http://acg.jhsph.org (accessed 2015 May 15).

32. Antoniou T, Zagorski B, Bayoumi AM, et al. Trends in HIV prevalence, new HIV diagnoses, and mortality among adults with HIV who entered care in Ontario, 1996/1997 to 2009/2010: a population-based study. Open Med 2013; 7:e98-106.

33. Antoniou T, Zagorski B, Macdonald EM, et al. Trends in live birth rates and adverse neonatal outcomes among HIV-positive women in Ontario, Canada, 2002-2009: a descriptive population-based study. Int 7 STD AIDS 2014;25: 960-6.

34. Ontario Community HIV/AIDS Reporting Tool (OCHART). Toronto: Ontario HIV Treatment Network; 2011. Available: www.ochart.ca/documents /Resources_Reports.htm (accessed 2015 June 7).

35. Wang EA, McGinnis KA, Fiellin DA, et al. Food insecurity is associated with poor virologic response among HIV-infected patients receiving antiretroviral medications. 7 Gen Intern Med 2011;26:1012-8.
36. Weiser SD, Hatcher A, Frongillo EA, et al. Food insecurity is associated with greater acute care utilization among HIV-infected homeless and marginally housed individuals in San Francisco. 7 Gen Intern Med 2013;28:91-8.

37. Kushel MB, Gupta R, Gee L, et al. Housing instability and food insecurity as barriers to health care among low-income Americans. 7 Gen Intern Med 2006;21:71-7.

38. Sayles JN, Wong MD, Kinsler JJ, et al. The association of stigma with selfreported access to medical care and antiretroviral therapy adherence in persons living with HIV/AIDS. 7 Gen Intern Med 2009;24:1101-8.

39. Kendall CE, Wong J, Taljaard M, et al. A cross-sectional, population-based study measuring comorbidity among people living with HIV in Ontario. BMC Public Health 2014;14:161.

40. Burchell AN, Gardner S, Light L, et al. Engagement in HIV care among persons enrolled in a clinical HIV cohort in Ontario, Canada, 2001-2011. 7 Acquir Immune Defic Syndr 2015;70:e10-9.

41. Remis RS, Liu J. HIVIAIDS in Ontario: preliminary report. Toronto: Ontario HIV Epidemiologic Monitoring Unit; 2011. Available: www.ohemu.utoronto. ca/doc/PHERO2011_report_preliminary.pdf (accessed 2016 Feb. 4).

42. Lambert AA, Kirk GD, Astemborski J, et al. HIV infection is associated with increased risk for acute exacerbation of COPD. 7 Acquir Immune Defic Syndr 2015;69:68-74.

Affiliations: Institute for Clinical Evaluative Sciences ( $\mathrm{Ng}$, Kendall, Loutfy, Raboud, Glazier, Antoniou), Toronto, Ont.; Department of Family Medicine (Kendall), University of Ottawa, Ottawa, Ont.; C.T. Lamont Primary Health Care Research Centre (Kendall), Bruyère Research Institute, Ottawa, Ont.; Dalla Lana School of Public Health (Burchell, Raboud), University of Toronto; Li Ka Shing Knowledge Institute (Burchell, Bayoumi, Antoniou), St. Michael's Hospital; Department of Family and Community Medicine (Burchell, Glazier, Antoniou), St. Michael's Hospital and University of Toronto; Centre for Research on Inner City Health (Bayoumi, Rourke), St. Michael's Hospital; Department of Medicine (Bayoumi, Loutfy), University of Toronto; Women's College Research Institute (Loutfy), Women's College Hospital; Toronto General Research Institute (Raboud), University Health Network; Department of Psychiatry (Rourke), University of Toronto; Ontario HIV Treatment Network (Rourke), Toronto, Ont.

Contributors: All authors contributed to the conception and design of the study. Ryan $\mathrm{Ng}$ and Tony Antoniou acquired the data, and all authors were involved in the analysis and interpretation of the data. Ryan $\mathrm{Ng}$ and Tony Antoniou drafted the manuscript, and all authors were involved in critical revision of the manuscript. Ryan $\mathrm{Ng}$ and Tony Antoniou provided administrative, technical or material support. All of the authors gave final approval of the version to be published and agreed to act as guarantors of the work.

Funding: This study was funded as an Applied Health Research Question through the Institute for Clinical Evaluative Sciences (ICES), which is funded by an annual grant from the Ontario Ministry of Health and Long-Term Care (MOHLTC). The sponsors had no role in the design or conduct of the study; in the collection, analysis or interpretation of the data; or in the preparation, review or approval of the manuscript. The opinions, results and conclusions reported in this paper are those of the authors and are independent from the funding sources. No endorsement by ICES or the Ontario MOHLTC is intended or should be inferred. Parts of this material are based on data and information compiled and provided by the Canadian Institute for Health Information (CIHI). However, the analyses, conclusions, opinions and statements expressed herein are those of the author, and not necessarily those of CIHI.

Acknowledgements: Tony Antoniou is supported by a New Investigator Award from the Canadian Institutes for Health Research-Ontario HIV Treatment Network. Ann N. Burchell is supported by a New Investigator Award from the Canadian Institutes for Health Research. Mona Loutfy is the recipient of salary support from Women's College Hospital, the University of Toronto and the Women's College Research Institute. Janet Raboud is supported by an Ontario HIV Treatment Network Chair in Biostatistics and the Skate the Dream Fund, Toronto and Western Hospital Foundation. Richard H. Glazier is a Clinician Scientist in the Department of Family and Community Medicine of St. Michael's Hospital and the University of Toronto.

Supplemental information: For reviewer comments and the original submission of this manuscript, please see www.cmajopen.ca/content/4/2/ E240/suppl/DC1. 